\title{
Improving Concrete Waste Rate Generation of Structure Projects in Leading Construction Firm in Indonesia
}

\author{
Daniela Dea Hapsari \\ Master of Mechanincal Engineering, \\ Swiss German University \\ Tangerang City, Indonesia \\ danieladhapsari@gmail.com
}

\author{
Sumarsono Sudarto \\ Master of Mechanincal Engineering, \\ Swiss German University \\ Tangerang City, Indonesia \\ sumarsono@mercubuana.ac.id
}

\author{
Gembong Baskoro \\ Master of Mechanincal Engineering, \\ Swiss German University \\ Tangerang City, Indonesia \\ gembong.baskoro@sgu.ac.id
}

\begin{abstract}
The Construction and Demolition (C\&D) industry is very close to various waste management issues as the generation of waste is inevitable in every construction. In Indonesia, to make an applicable implementation of $C \& D$ Waste Management, the improvement must be made by looking into the actual field process. The improvement uses DMAIC as the lean tools and VSM to state the current process of material from its delivery on the site into a waste. Waste that is being monitored is the most used materials in the case study project which are concrete. A notable project was taken for the study as it will help other structure projects to imitate the down-to-earth future state, aiming at the reduction of waste generation rate and also business process improvement. The result shows that the process of concrete from orders to waste took eight steps, and three of them are improved, producing $3 \%$ lesser waste from the current state. The best scenario WGR were analyzed to also answer the stakeholder interest within the case study.
\end{abstract}

Keywords—component, formatting, style, styling, insert.

\section{INTRODUCTION}

It is known that only $1-2 \%$ of the $C \& D$ are recycled, while actually the construction industry responsible to borne energy and natural resources that consumed globally up to $40 \%$ [1-2] The compositions of waste are mater in order to understand how to do the $3 \mathrm{R}$ cycles of waste handling. The reduce, re-use and re-cycle as its order of abbreviations speaks the step-by-step wastage control. Many waste management research has come into second step which is the re-use and re-cycle but to achieve the optimum result, in-situ improvement such as doing a reduction on the production stage of wastage is crucial as shown in Fig. 1.

The management of waste in project management and construction is actually similar to another industry sector, where less waste equals better environmental impact and good cost handling. Many industries used various lean tools to understand how to optimize the process and wastage. Principles of tools in lean manufacturing such as VSM (Value Stream Mapping) as one of the most used tools have proven fruitful in engaging the employee on understanding the targeted improved process but still, only a few are implemented into other industry while the tools itself can be exploited into few other applicable issues.

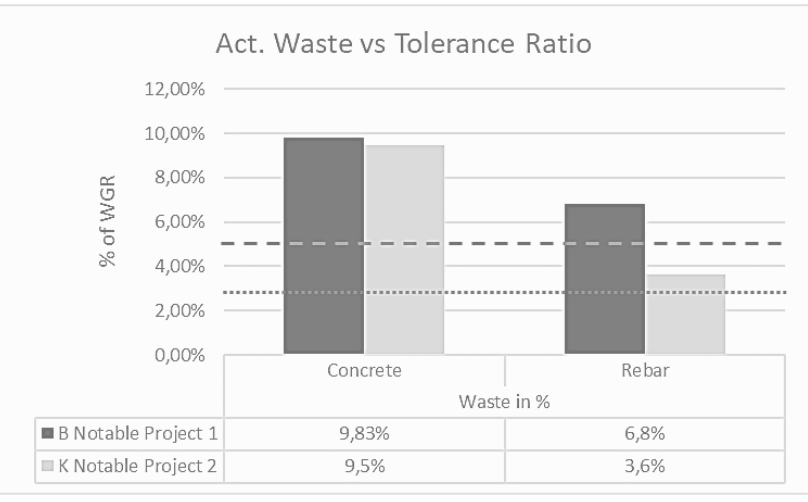

Fig. 1. Actual waste generation rate vs the tolerance ratio of notable high rise building structure projects

Lean management approach was chosen to help the project into better business process, that dependent on mutual understanding, agreement, a clear information sharing and trust. On the other hand, the board of directors' interest to ensure the improvement are impactful to the field, environment, and also the business will be analyzed through WGR Improvement analysis.

The analytical perspective upon Waste Generation Rate aims not only for the rate but also for the cost savings, time efficiency, quality robust system, and safety aspects where the environment takes part. The WGR of concrete waste improvement will be a great example of comprehensive changes, targeting also human and economic aspects of the worker involved, as researched previously by Fercoq et al., [3]. The total benefits and modification cost is mentioned to strengthen the argumentation of this research.

The research question is then how to improve the waste generation rate in structure High Rise Building (HRB) project of concrete material. The Objective of the paper is to get improvement on the wastage handling and by designing the future state of improvement. Expected result is to get a lower WGR of concrete material produced and time efficiency discrepancy. 


\section{A. Scope and Limitation}

This research scope are limited to these following points:

1. Taken from the project in the category of structure construction (sub structure) of a high rise building (HRB). The result specific to improve the HRB concrete waste.

2. Regulations and policy compliance referring to the local government in Jakarta at year of 2020.

3. Green building marks taken into considerations but the result not targeting to fulfill the green building points and marks.

4. The research looked into period of waste produced from the early stage of the project (2016) until the latest data collection of concrete waste (end 2019).

5. The $\mathrm{C} \& \mathrm{D}$ material being elaborated is concrete materials as the reasoning mentioned in the background.

\section{LITERATURE REVIEW}

\section{A. Waste Generation Rate of Concrete}

The waste generation rate of concrete calculated from the amount of concrete ordered (and stored by the systems of Purchasing Order through SAP) divided by the amount of concrete settle down the work floor of the needing area of structure project, times $100 \%$. The Waste generation rate are highly dependent on the rules and policy applied to the certain projects. In the research object study, processes like samples taking, testing of concrete curing and the re-use material are consider the waste, making the rate of WGR fulfillment in the concrete are rather tight compare to the actual field equitation.

Concrete as the main topic in this research has many inputs from previous researcher, expert, and application such as: (1) Aggregates for other structural concrete, (2) general filling in the pavement of construction site, (3) road base material, (4) soil stabilization material, (5) addition works like car stopper in the parking area, and (6) ramp border. Many usages of waste remaining in the pipe of concrete pump that needed to be extracted right after the casting process done as previously mentioned is commonly done by the project managers and supervisors instantaneously. This is also considered as a re-use steps of $3 \mathrm{R}$ cycles of waste minimalization. As the decision making about where the concrete waste should go is not standardize and tend to be more spontaneous and adjusting with the needs of the operations at particular time, it is more important to seek into bigger picture of CWM handling instead of looking only the alternatives of where should the remaining fresh concrete should go.

The challenges among waste management stated in the Table 1 mostly goes around WGR (Waste Generation Rate) [1], waste compositions and performance operations [4], 3R waste cycles [5], circular economy impact [6], or early improvement at the beginning of the design stage [7]. The challenge met by wide range of waste produced by different industries enriched the perspective of waste handling.
TABLE I

MOST RELATED RESEARCH DIMENSION OF WASTE

\begin{tabular}{lccc}
\hline \multirow{2}{*}{ Authors, Years } & \multicolumn{3}{c}{ Waste dimension } \\
\cline { 2 - 4 } & WGR & MGT & Sust. \\
\hline \hline Hoang,et al, 2020 & $\checkmark$ & $\checkmark$ & - \\
\hline Reyes, et al, 2018 & - & $\checkmark$ & - \\
\hline Umar, 2019 & $\checkmark$ & $\checkmark$ & - \\
\hline Fatimah, et al, 2019 & - & $\checkmark$ & $\checkmark$ \\
\hline Xu and Lu, 2019 & - & $\checkmark$ & - \\
\hline Fercoq, et al, 2013 & & $\checkmark$ & $\checkmark$ \\
\hline
\end{tabular}

Specific waste dimension analyzed on this research aims to improve the Waste Generation Rate that has direct impact to the overall waste performance within the project operational excellence mindset. Management parts of the waste handling come as the second later of wastage control to cover up many corresponding aspects of WGR. Management parts emphasize on the human factor, culture mindset of the worker and early reduction that set by design.

\section{B. Lean Tools, DMAIC and Value Stream Mapping}

In most related research of concrete improvement in many industries, including construction, the lean tools can be found in many research as shown in Table 2. The applicable and benefit fit more to the current needs of operation, where the goals are to bring fast and efficient results and process. The Value stream mapping, are mostly found in manufacture industry, are now very common to be found in the construction industry. While Reyes et al. [4] shows the extention of VSM tools by enhancing them with environment aspects, some of other researcher shows that DMAIC tools can be the enrichment of the VSM applications. The PDCA and other approach like statistics data and IoT also provides a wider perspective and parameters, but for this case study, the VSM tools and DMAIC are judged to be the most suitable tools for the analysis.

TABLE II

TOOLS OF ANALYSIS IN MOST RELATED RESEARCH

\begin{tabular}{lcccc}
\hline \multirow{2}{*}{ Authors, Years } & \multicolumn{4}{c}{ Tools } \\
\cline { 2 - 5 } & VSM & DMAIC & PDCA & Other \\
\hline \hline $\begin{array}{l}\text { Hoang,et al, } \\
2020\end{array}$ & - & - & - & IAQ \\
\hline $\begin{array}{l}\text { Reyes, et al, } \\
2018\end{array}$ & $\begin{array}{l}\checkmark(\mathrm{E}- \\
\text { VSM })\end{array}$ & - & $\checkmark$ & - \\
\hline Umar, 2019 & - & - & - & SPSS \\
\hline $\begin{array}{l}\text { Fatimah, et al, } \\
2019\end{array}$ & - & - & - & IoT \\
\hline $\begin{array}{l}\text { Xu and Lu, } \\
2019\end{array}$ & - & $\checkmark$ & - & DfCWM \\
\hline $\begin{array}{l}\text { Fercoq, et al, } \\
2013\end{array}$ & & $\checkmark$ & $\checkmark$ & \\
\hline
\end{tabular}

\section{RESEARCH METHOD}

General method of this research consist of six main steps, see Fig. 2. Start from the preliminary research, which 
applying the CDW (Construction \& Demolition Waste) quantification in the site based on Image Analysis adapted from Hoang et al. [1] and CW estimation similar to Guerra et al. [8] to get the actual data of waste produced by the contractor and supplier. The image quantification method is very beneficial to establish an accurate wastage percentage that later are combined with the report form the Quantity Surveyor within the monthly report. Second, the preliminary research enriched by understanding the material flow and information, taken by doing a deep interview with the expert in the field. The interview will be fruitful to seek the unseen event on the project, since not every routine can be monitored during the image quantification analysis. The indepth interview is taken separately from the first step and continue during the research to stay related and applicable. The third, is to do object (concrete) quantification, measuring the data related to the customer demand, time needed in each production process and record them [9]

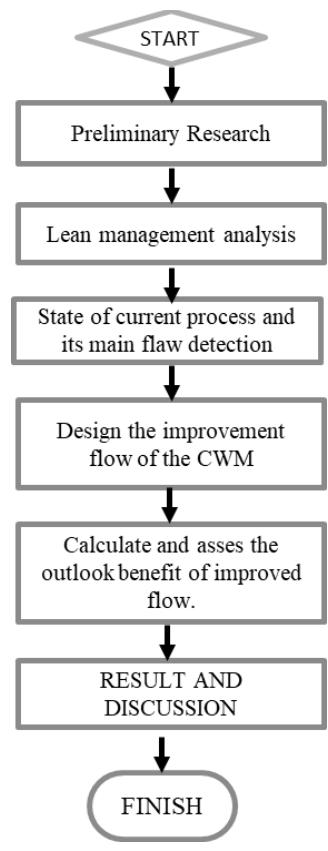

Fig. 2. Research method

\section{RESULTS}

Results of the improvement using the method stated in previous chapter will be explained within this section. The result consists of few points that are parts of the stepping logic of the improvement of waste generation rate. The improved WGR after the analysis served at the last section.

\section{A. Preliminary research result}

The first stage which are the preliminary research occurred before everything to get this following information:

1. The on-site image analysis to obtain the number of wastes generated from a process flow.
2. Interview with the project administration mangers to obtain series of material flow and information flow

3. Further information to get the overall process of the concrete material from the very beginning of the design state until the declaration of waste generation rate and the report submitted to the stakeholders.

4. Process of material lifecycle at the construction.

\section{B. Current State}

By default, the value stream mapping tools provides series of attributes to help researchers state the current flow of the targeted improvement process. In this case is the concrete material. The current state can be illustrated like the following Fig. 3.

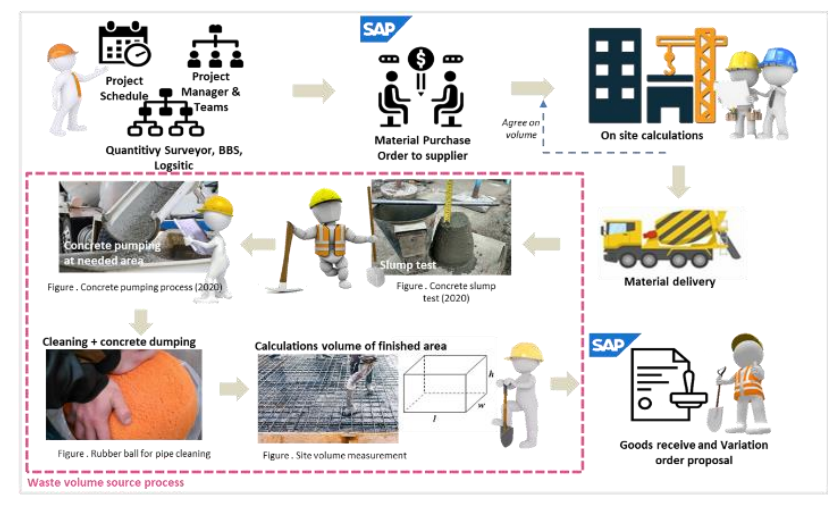

Fig. 3. Current flow of concrete materials

By matching the parameters into VSM attributes, the current state can be drawn like Fig. 4 . Where overall, there are 8 main steps explained by the square boxed beneath the information flow. The 8 processes are:

1. On site calculations

2. Purchase order

3. Material receives

4. Slump test

5. Concrete pumping

6. TM Clean up and dumping

7. Curing and GR Check

8. VO \& Wastage calculations.

\section{DMAIC Analysis}

The following process after understand the current state of the concrete material are the analysis of the improvement. Three out of 8 process are detected to be fixed and labeled with the "Kaizen Burst" where the improvement proposed are targeting a quick, implementable and down to earth improvements that can be applied right away at the projects or installations. 


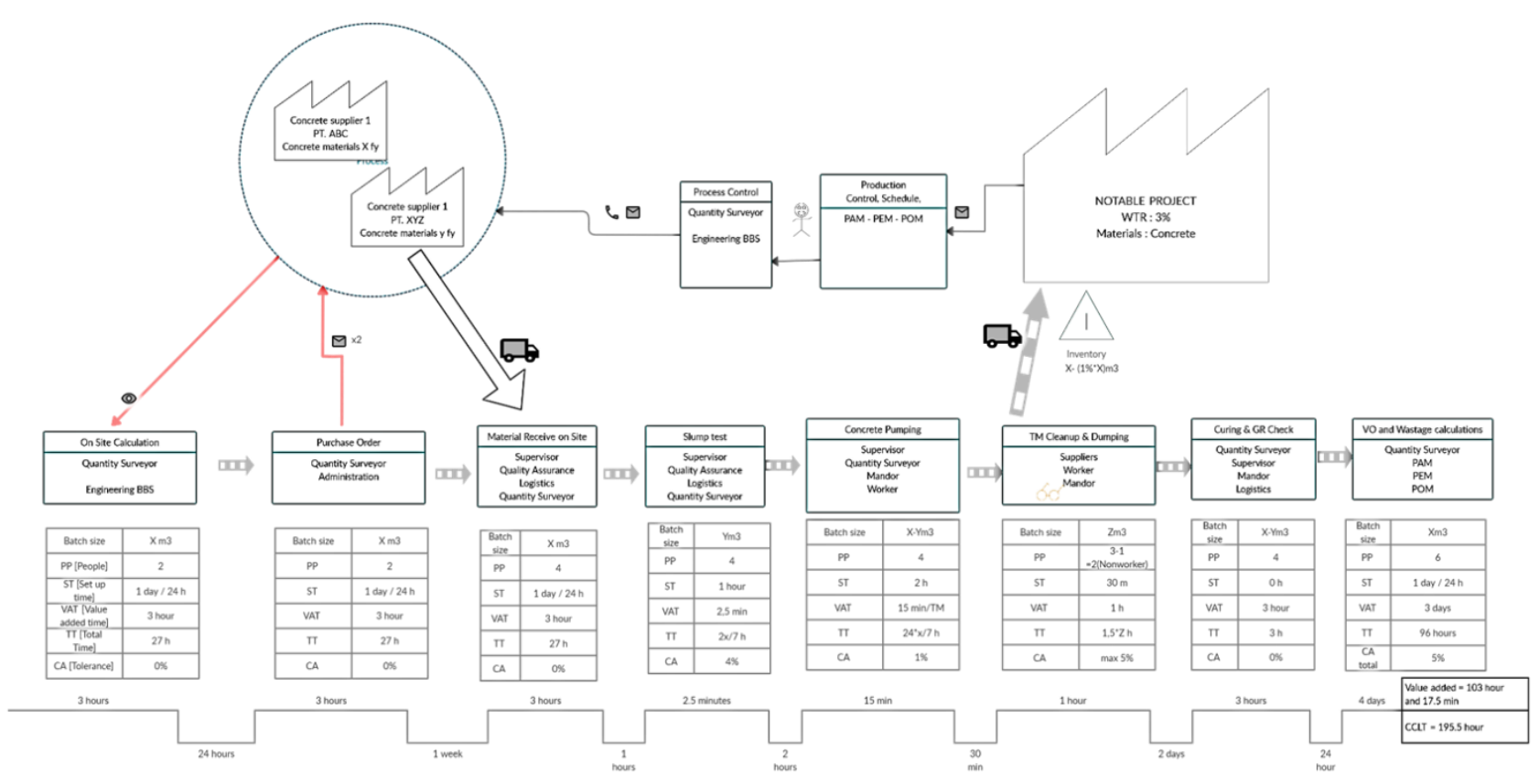

Fig. 4. Current state

TABLE III

LIST OF PROCESS BOX AND THE KAIZEN BURST TAG

\begin{tabular}{cl}
\hline No. & Process of material \\
\hline 1 & Insitu calculations \\
\hline 2 & Purchase order \\
\hline 3 & Material receive \\
\hline 4 & Slump test* \\
\hline 5 & Concrete Pumping \\
\hline 6 & TM Cleanup and dumping* \\
\hline 7 & Curing \& GR Check \\
\hline 8 & VO \& Wastage calculations* \\
\hline \hline
\end{tabular}

*Process with the Kaizen burst

The DMAIC Analysis specified into the three most beneficial process box which are the (1) Slump test, (2) TM Clean up and dumping, (3) VO \& Wastage calculations. The parameter being measured are the: (1) People, (2) Set up time, (3) Value added time, (4) Total time to complete and (5) Completion accuracy of the tolerance of error.

Process boxes with the kaizen burst tag are improved and can be summarized like Table 3 .

1. The Define stage consist of the understanding of what parameters that can be improved, the particular information in preliminary research fulfill this define stage.

2. Measure stage of the process are obtained also during the preliminary research, by interview and on site facts data.
3. Analyze stage of the process are taken from business process analysis, understanding the room of improvement and excess flow and people handling

4. Improve stage are when the propose model are raised into considerations of the new flow, ensuring also that the proposed model can be implemented quickly and the result are expected to be seen within less than a month.

5. Control stage are the last stage of the DMAIC analysis, this particular stage is highly dependent on the importance of the issue raise top-down by the management. Commitment of the control phase are raised form the head office to the structure project, targeting a universal implementation program of the structure projects to obey the waste generation policy.

The summary of the kaizen-tagged process is stated in the Table 3.

\section{Future State}

The future state is then mapped out once again to serve a new map of process, including the aspects that follows the process. The future state also indicates detail which process are being improved and how is the propose mode targeting the improvements. The future state must be mapped out using the same attributes and the result of the DMAIC analysis in the previous sub chapter, results in the Fig. 5. 


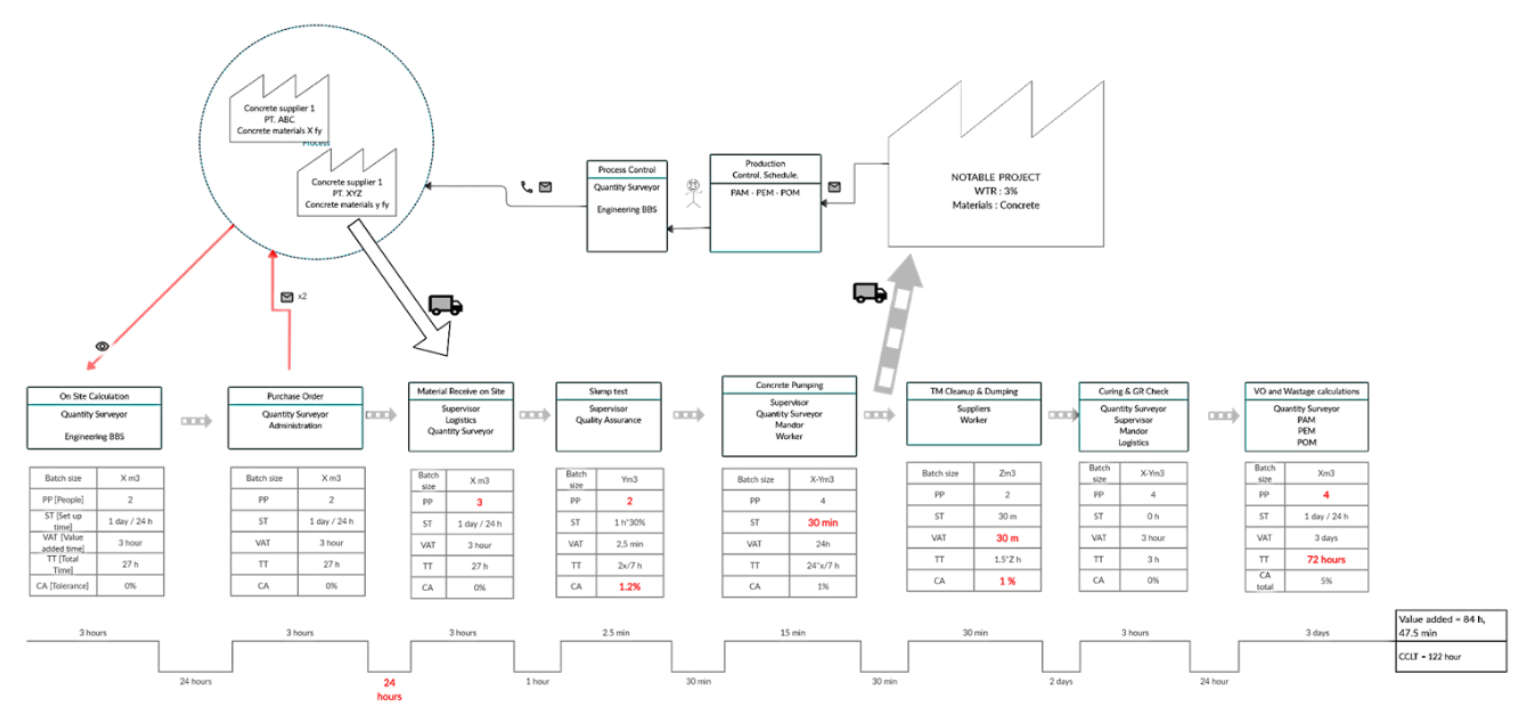

Fig. 5. Future state

TABLE IV

OUTLOOK OF WGR IMPROVEMENTS.

\begin{tabular}{|c|c|c|c|}
\hline \multirow{2}{*}{ No. } & \multirow{2}{*}{ MATERIAL FLOW } & \multicolumn{2}{|c|}{ Waste Completion Accuracy Tolerance } \\
\hline & & Current state & Future state improvement \\
\hline 1 & On site calculations & $3,0 \%$ & $3,0 \%$ \\
\hline 2 & Purchase Order & $2,0 \%$ & $2,0 \%$ \\
\hline 3 & Material receive & $0,0 \%$ & $0,0 \%$ \\
\hline 4 & Slump test & $4,0 \%$ & $1,2 \%$ \\
\hline 5 & Concrete pumping & $1,0 \%$ & $1,0 \%$ \\
\hline 6 & TM Cleanup \& dumping & $5,0 \%$ & $1,0 \%$ \\
\hline 7 & Curing\&GR Check & $0,0 \%$ & $0,0 \%$ \\
\hline 8 & VO \& Wastage calculations & $5,0 \%$ & $5 \%$ \\
\hline Total Concrete delivered & & & $153.097,72$ \\
\hline Total WCA & (total of WCAT) & $20,00 \%$ & $13,20 \%$ \\
\hline WGR & (based on report project 2017-2019) & $9,83 \%$ & $6 \%$ \\
\hline Volume of Waste & (Actual in \% $\times$ Total Concrete delivered) & $15.049,51$ & $9.932,67$ \\
\hline Waste Coefficient & (WCAT/Actual waste precentage) & 2,03 & 2,03 \\
\hline \multirow{2}{*}{ Savings } & in Concrete volume & & $5.116,83$ \\
\hline & in IDR & & 5.705.267.756 \\
\hline
\end{tabular}

\section{E. Improvements of Waste Generation Rate}

After the future state are improved, the waste generation rate can be calculated as the outlook of improvements. As seen in the Table 4, the WGR are improved from $9.83 \%$ to $6 \%$. The targeted tolerance was $5 \%$ stated by the contract to the projects, and the achievement after analysis still have remaining $1 \%$ to achieve the goals. However, the improvement upon the rate still can be achieved because the kaizen tag burst limits the improvement into few processes box only, neglecting the whole process that might be helpful to bring another $1 \%$ to the result so the requirement can be fulfilled.

\section{F. Conclusions}

The research concluded that:

1. The research has developed new design of the improved waste management system in structure project focusing on the optimum rate of waste generation rate.

2. It finds that the performance of waste generation rate could be improve from $9,83 \%$ to $6,49 \%$ So the system now has been improved at around $3 \%$ of its performance.

3. The research contributes to the academic area by providing a novel method for improving a better waste management system specialized in notable project of structure, build in the heart of capital city of Indonesia.

4. The research helps the project managers to understand that VSM and DMAIC is a powerful 
tool to seek the room of improvement in order to minimize waste and set applicable refinements.

\section{REFERENCES}

[1] [1] N. H. Hoang, T. Ishigaki, R. Kubota, T. K. Tong, T. T. Nguyen, H. G. Nguyen, M. Yamada, and K. Kawamoto, "Waste generation, composition, and handling in buildingrelated construction and demolition in Hanoi, Vietnam," Waste Management, 117, pp. 32-41, 2020. https://doi.org/10.1016/j.wasman.2020.08.006

[2] M. Asif, T. Muneer and R. Kelley, "Life cycle assessment: A case study of a dwelling home in Scotland," Building and Environment, 42 (3), pp. 1391-1394, 2007. https://doi.org/10.1016/j.buildenv.2005.11.023

[3] A. Fercoq, S. Lamouri, V. Carbone, A. Lelièvre, and A. A. Lemieux, "Combining lean and green in manufacturing: A model of waste management," In IFAC Proceedings Volumes (IFAC-Papers Online) $46 \quad$ (9). 2013. https://doi.org/10.3182/20130619-3-RU-3018.00164

[4] J. A. G. Reyes, J. T. Romero, K. Govindan, A. Cherrafi, and U. Ramanathan, "A PDCA-based approach to environmental value stream mapping (E-VSM)," Journal of Cleaner Production, 180, pp. 335-348, 2018. https://doi.org/10.1016/j.jclepro.2018.01.121
[5] U. A. Umar, N. Shafiq, and F. A. Ahmad, "A case study on the effective implementation of the reuse and recycling of construction and demolition waste management practices in Malaysia," Ain Shams Engineering Journal, 2020. https://doi.org/10.1016/j.asej.2020.07.005

[6] Y. A. Fatimah, K. Govindan, R. Murniningsih and A. Setiawan, Industry 4.0 based sustainable circular economy approach for smart waste management system to achieve sustainable development goals: A case study of Indonesia. Journal of Cleaner Production, 269, pp. 122263, 2020. https://doi.org/10.1016/j.jclepro.2020.122263

[7] J. Xu and W. Lu, "Design for construction waste management. Sustainable Buildings and Structures: Building a Sustainable Tomorrow, July, pp. 271-276, 2019. https://doi.org/10.1201/9781003000716-36

[8] B. C. Guerra, F. Leite, and K. M. Faust, "4D-BIM to enhance construction waste reuse and recycle planning: Case studies on concrete and drywall waste streams," Waste Management, 116, pp. 79-90, 2020. https://doi.org/10.1016/j.wasman.2020.07.035

[9] N. Nandakumar, P. G. Saleeshya, and P. Harikumar, "Bottleneck identification and process improvement by lean six sigma DMAIC methodology," Materials Today: Proceedings, 24, pp. 1217-1224, 2020 https://doi.org/10.1016/j.matpr.2020.04.436 